\title{
Role of HR-HPVs E6 and E7 Oncoproteins in Cervical Carcinogenesis
}

Patricio Gariglio $^{1^{*}}$, Jorge Organista-Nava ${ }^{1,2}$ and Elizabeth Alvarez-Rios ${ }^{1}$

${ }^{1}$ Departamento de Genética y Biología Molecular, Centro de Investigación y de Estudios Avanzados del Instituto Politécnico Nacional (CINVESTAV), México

${ }^{2}$ Programa de Doctorado en Ciencias Biomédicas, Instituto de Fisiología Celular (IFC), Universidad Nacional Autónoma de México (UNAM), México

*Corresponding author: Patricio Gariglio, Department of Genetics and Molecular Biology, Centro de Investigación y de Estudios Avanzados del IPN, Av. IPN 2508. Colonia San Pedro Zacatenco, Ciudad de México C.P. 07360, México, Tel: 525557473337; Fax: 525557473931; E-mail: vidal@cinvestav.mx

Received date: February 29, 2016; Accepted date: May 12, 2016; Published date: May 17, 2016

Copyright: (C) 2016 Gariglio P, et al. This is an open-access article distributed under the terms of the Creative Commons Attribution License, which permits unrestricted use, distribution, and reproduction in any medium, provided the original author and source are credited.

\begin{abstract}
The strategies that High Risk Human Papillomavirus (HR-HPVs) have developed in differentiating epithelial cells to reach a DNA-synthesis competent state are basically related to the overexpression of the E6 and E7 oncoproteins and the cellular regulatory pathways that are targeted by them. These are basically related to hallmarks of cancer, and include sustaining proliferative signals, the evasion of growth suppression and immune destruction, replicative immortality, inflammation, invasion, metastasis and angiogenesis, as well as genome instability, resisting cell death and deregulation of cellular energetics. In this minireview, we summarize some of the biological activities of HVP16 E6 and E7 oncoproteins in cervical carcinogenesis. From this, it is evident that cervical cancer may represent an important model to understand the different oncogenic mechanisms and processes involved not only in this neoplasia but also in the development of other human malignancies. Likewise, the miRNAs and cancer stem cellrelated markers expression could serve as novel molecular targets for the diagnosis and treatment of HPV positive cervical cancer.
\end{abstract}

Keywords: Cervical carcinogenesis; E6 Oncoprotein; Oncoprotein; HR-HPV; Molecular mechanisms of oncogenesis

\section{Introduction}

There are more than 150 distinct types of cancer, and several subtypes are found for each particular neoplasia. Viruses are the causative agents of approximately $12 \%-15 \%$ of all cancers worldwide [1]. Fortunately, not all individuals infected with oncogenic viruses develop cancer; persistently infected individuals are at-risk for cancer development but other risk factors must be considered [2,3]. Human viral oncogenesis is complex and only a small percentage of the infected individuals develop cancer and often many years to decades after initial infection. This reflects the genetic variability of the host and the fact that viruses contribute to only a portion of the multistep oncogenic events [4]. Progression to cancer as a result of infection with an oncogenic virus is usually a rare event. For example, the overall prevalence of high-risk alpha HPV (HR-HPV) infection is approximately $23 \%$ [5]; most of these infections clear up spontaneously (about $90 \%$ clear within two years). Only $0.3 \%$ to $1.2 \%$ of these initial infections will eventually progress to invasive cervical cancer $[2,6]$. A small group of HR-HPVs (particularly HPV16 and HPV18) infects mucosal epithelial cells and is the major cause of almost all cases of cervical carcinoma (second cause of cancer death in women), as well as other anogenital cancers and almost 40 percent of oral carcinomas [4].

HR-HPVs can establish long-term persistent infection of epithelial cells, therefore successfully avoiding immune surveillance. In general, HR-HPV-infected cells are rapidly eliminated by the immune system, despite the transforming properties of the viral E6 and E7 oncoproteins, and they do not have sufficient time to accumulate chromosomal abnormalities to acquire a malignant phenotype. Thus, the establishment of a chronic infection blocking immune surveillance is very important for the development of HPV-associated malignant diseases. Although it is clear that HR-HPV E6 and E7 target cellular pathways related to innate and adaptive immunity, host and environmental factors significantly contribute to persistent HR-HPV infection [1]. It is worth mentioning that E6 and E7 can each hinder innate immunity by inhibiting interferon signaling [7] and that the viral E5 proteins can downregulate MHC class I expression. Inflammation has been linked to HPV associated cancers but it is unknown whether and/or how HPVs may trigger inflammation. There are recent reviews on HPV mechanisms responsible for the deregulation of immune-response-related pathways $[8,9]$.

The strategies that these HR-HPVs have developed in differentiating epithelial cells to reach a DNA-synthesis competent state are basically related to the overexpression of the E6 and E7 oncoproteins and have the potential to induce cancer development [10,11]. One of these strategies is the frequent integration of the viral genome into the host genome (Figure 1). Under these conditions, viral oncoproteins are expressed but no infectious viral progeny is produced. It is well known that expression of the viral transforming proteins is tightly controlled during normal productive HPV infections and infected cells only rarely undergo malignant transformation. Dysregulated HPV E6 and E7 expression as a consequence of integration of viral sequences into the host genome (Figure 1) or due to epigenetic alterations of the viral genome puts cells at a higher risk for undergoing oncogenic transformation. The first indication of the oncogenic properties of E6 and E7 was provided by studies on cervical cancer-derived cell lines in which viral DNA was found randomly integrated in the host genome, leading to the disruption of several viral genes (particularly E2, that codes for a repressor of the viral long control region or LCR) and preservation of the E6 and E7 oncogenes, which are actively transcribed. Many studies have shown that the frequency of viral DNA integration increases with the severity of the cervical lesion, indicating that this event is implicated in the progression of the disease [12]. Continuous E6 and E7 expression is necessary for the maintenance of the malignant phenotype. A key role of E6 and E7 oncoproteins in HR- 
HPV-mediated carcinogenesis has been suggested by the ability of E6 and E7 to induce transformation of immortalized rodent fibroblasts, and to immortalize primary human keratinocytes [13]; however, HPVimmortalized cells are not tumorigenic in nude mouse models and they can form tumours only after expression of cellular oncogenes or extensive passaging in cell culture [1,11], suggesting that E6 and E7 expression is necessary but not sufficient for full malignant transformation.

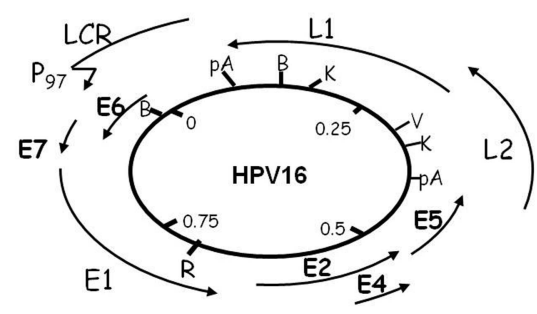

Integration into Cellular Genome

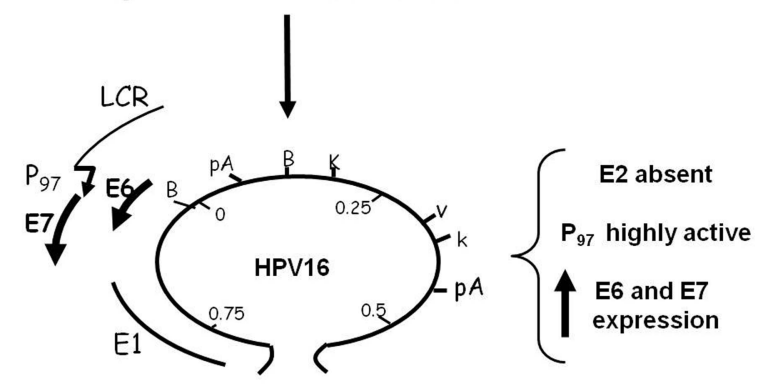

Figure 1: Integration of the viral genome into the host genome, followed by overexpression of E6 and E7 oncoproteins.

Integrated HPV sequences consisting mainly of the LCR and E6/E7 oncogenes are found in many HR-HPV-positive cervical carcinomas. Integration frequently occurs at common fragile sites of the human genome and in some cases can lead to increased expression of cellular proto-oncogenes. When HR-HPV episomes are maintained in cancers, E6/E7 expression may be upregulated in part by epigenetic alterations of the LCR [4,7]. Thus, overexpression of these viral oncoproteins is an important step in HR-HPV carcinogenesis.

Since high-risk E6 and E7 do not bind to gene promoter regions and lack enzymatic activities they exert their functions by associating with a vast number of cellular proteins $[10,11,14,15]$, activating multiple cancer hallmarks $[1,4]$. We will briefly discuss in this minireview some properties of E6 and E7, as well as the participation of these viral oncoproteins in the deregulation of miRNAs expression and acquisition of cancer stem cells (CSCs) characteristics.

\section{E6 and E7 Oncoproteins of HR-HPVs}

E7 is a phosphoprotein of approximately 100 amino acids that contains a short motif that mediates the interaction with the retinoblastoma tumor suppressor protein $(\mathrm{pRB})$ and its related proteins p107 and p130. These proteins are linked to cell cycle control and are degradated by the HR-HPV E7 oncoprotein. pRB normally binds and inactivates E2F1-3 transcription factors, maintaining the cell in a quiescent state in the $\mathrm{G}_{0} / \mathrm{G} 1$ phase of the cell cycle. The HR-HPV E7 proteins target the active dephosphorylated form of $\mathrm{pRB}$ for proteosomal degradation. This activates E2F-regulated transcription, which includes the transcription of cyclin A and cyclin E. These cyclines are positive regulators of cyclin-dependent kinases (CDKs) inducing cell cycle progression and sustained proliferative signaling. Degradation of pRB also inhibits the oncogene-induced senescence response that is triggered by $\mathrm{E} 7$ expression and is signaled by the CDK4/CDK6 inhibitor p16INK4A; evasion of growth suppressors and uncontrolled S-phase entry leads to p53 tumor suppressor activation, which triggers apoptosis. To resist cell death, high-risk HPV E6 proteins target p53 for degradation via the ubiquitin pathway and the E6-associated protein E6AP (see later). E7 can also strongly stimulate the histone $\mathrm{H} 1$ kinase activity of CDK2 in complex with either cyclin A or cyclin E. The other two pRb-related proteins, p107 and p130, are part of co-repressor complexes containing histone deacetylases and other members of the E2F family [16,17]. It was determined that HPV16 E7 destabilizes p130 [18], probably changing the inhibitory functions of the E2F complexes. E2F6 interacts with polycomb complexes [19,20], and induces epigenetic changes associated with gene silencing, such as trimethylation of lysine 27 on histone $\mathrm{H} 3$ (H3K27me3). HPV16 E7 interacts with E2F6 and interferes with the inhibitory function of E2F6 [21]. In addition, HPV16 E7 expression causes epigenetic reprogramming of cells at the level of both DNA methylation and histone modifications. HPV16 E7 expression reduces the global H3K27me3 mark, releasing polycomb repressive complex (PRC)-mediated repression [22]; interestingly, E7 induces the expression of KDM6B, H3K27me3 specific demethylase contributing to the transcriptional activation of important cellular genes such as p16 [22]. This tumor suppressor gene is not the only one induced by E7 since RARB was also overexpressed by this oncoprotein both in vitro and in the cervix of young E7-transgenic mice [23]. E7 can also enhance transcription of several genes by the activation of histone acetyltransferases (HATs) and inhibition of histone deacetylases (HDACs), leading to an increase in global $\mathrm{H} 3$ acetylation [24,25]. All the mechanisms mentioned above are involved in the reprogramming of host epithelial cells to avoid cell cycle control [26]. Additionally, E7 deregulates the cell cycle by direct binding to the CDK inhibitors p21 and p27, blocking their cell cycle inhibitory effects [27]; it can also interact and activate cyclin A/CDK2 complexes [28]. The interaction of HPV16 E7 with CDK complexes is mainly mediated by the cyclin subunits [29]. Thus, the E7 oncoprotein interacts with a large number of cellular proteins, and targets multiple cellular pathways, many of them described in several recent reviews $[1,10,11,30]$.

On the other hand, transgenic mice expressing only the HPV16 E7 oncoprotein (K14E7 transgenic mice model) induce cervical cancer after 6 months of treatment with the $17 \beta$-estradiol [31,32], a steroid hormone found to be a risk factor for HPV-related cervical carcinogenesis [3]. The global genes expression profile in cervical tissue of young (1.5 month-old) adult K14E7 transgenic mice without estrogen treatment, indicated that the E7 oncoprotein altered the transcriptional pattern of genes involved in several biological processes including signal transduction, metabolism, cell adhesion, apoptosis, cell differentiation, as well as inflammatory and immune response [33]. Among the E7-dysregulated genes were ones not previously known to be involved in cervical neoplasia including DMBT1, GLI1 and $17 \beta$ HSD2. Employing the same cervical cancer mice model, CortesMalagon et al, assessed the global gene expression profiles induced by the HPV16 E7 oncoprotein and/or 17 $\beta$-estradiol in cervical tissue of non-transgenic and K14E7 transgenic mice, finding dramatic changes in gene expression both in the absence or presence of $17 \beta$-estradiol. A 
large number of differentially expressed genes involved in the immune response were observed in $17 \beta$-estradiol treated groups. Interestingly, the E7 oncoprotein mainly affected the expression of genes involved in cellular metabolism. Microarray data also identified differentially expressed genes that have not previously been reported in cervical cancer. The identification of genes regulated by E7 and $17 \beta$-estradiol, provides the basis for further studies on their role in cervical carcinogenesis [34].

E6 is a basic protein of approximately 150 amino acids containing two zinc-binding regions capable to associate and degrade many cellular proteins $[7,35]$, including the proapoptotic p53. The E6/E6AP complex binds to the central region of p53, which becomes rapidly ubiquitinated and targeted to proteasomes [36]. HR-HPV E6 oncoproteins have developed an additional mechanism to inhibit the apoptotic response via Bak degradation, which is a member of the Bcl-2 family [37]. This activity is also mediated by the interaction with E6AP and the ubiquitin-proteasome pathway. E6 also inhibits apoptosis through the proteolytic inactivation of pro-apoptotic proteins such as $\mathrm{p} 53$, FADD, or caspase-8, employing the ubiquitin proteasome pathway, or through interactions with proteins that form the death-inducing signaling complex (DISC) such as TNF-R1 [38]. The degradation of p53 by E6 is important because p53 is a transcription factor that regulates the expression of genes encoding regulators of cell cycle, DNA repair machinery, metabolism and apoptosis. Under cellular stress, such as oncogene activation, hypoxia or DNA damage, p53 triggers cell cycle arrest or apoptosis to guarantee the integrity of the cellular genome. By blocking the cell cycle, p53 prevents the replication of damaged DNA and, after activating the expression of genes involved in DNA damage repair, allows the cell to repair damage before $S$ phase. Alternatively, if DNA damage is too great and difficult to repair, p53 can induce apoptosis, thus preventing the production of potentially transformed progeny [39]. HR-HPV E6 is also able to inhibit the expression of p53-regulated genes by directly altering the transcriptional activity of CBP and p300 [40,41]. Among the targets of the HR-HPV E6 oncoprotein are members of the membrane-associated guanylate kinase (MAGUK) family [15]. These proteins contain various protein/protein interaction domains including PDZ domains that regulate cell-cell contact and cell polarity. E6 from HR-HPV types has a PDZ-binding motif at the C-terminus that mediates the interaction with MAGUK family members. This leads to degradation of MAGUK, with consequent loss of cell-cell contact, cell polarity and transforming properties $[42,43]$. In addition to what has been described above, a large number of E6 targets has been identified $[10,11,14,44]$. Regarding immortality, the HPV E6 protein stimulates telomerase expression and activity, thereby enabling replicative immortality [10,11]. E6/E6AP complex is also involved in the transcriptional activation of the hTERT (human telomerase reverse transcriptase) gene, which encodes the catalytic subunit of the telomerase complex $[45,46]$. Somatic cells are characterized by very little or no telomerase activity and telomeres shorten as a function of cellular division to finally reach a critical size, leading to replicative senescence. In contrast, HPV16-infected cells display a very high level of telomerase activity, allowing telomere length maintenance and indefinite proliferation. HPV16 E6 is able, through its association with E6AP, to promote the degradation of the transcriptional repressor NFX1-91, and consequently to activate hTERT transcription [47]; this repressor has also a role in HPV16 E6 activation of the oncogenic transcription factor NF-кB [47]. Interestingly, HPV16 E6 binds and cooperates with Myc in hTERT promoter activation [48].

\section{Regulation of Energy Metabolism by HR-Hpvs E6 and E7 Oncoproteins}

Cancer cell metabolism can be disrupted by mutated or epigenetically altered oncogenes and tumor-suppressor genes. Similarly, mutated metabolic enzymes can facilitate malignant transformation. The characteristic hallmark of tumor metabolism is aerobic glycolysis or the Warburg effect (a shift from oxidative phosphorylation to aerobic fermentation). Unlike normal cells that produce energy mostly through the oxidation of pyruvate in the mitochondria, cancer cells predominantly produce energy via enhanced glycolysis in the cytosol, even under aerobic conditions. Most cancer cells use glycolysis as a mean of energy production regardless of whether they are under normoxic or hypoxic condition. Recent studies revealed that in addition to aerobic glycolysis many cancer cells are capable to synthesize ATP through mitochondrial respiration [49]. Regardless of mitochondrial respiration status, cancer cells exhibit high rates of glycolysis and lactate fermentation [50].



Figure 2: HR-HPV E6 could increase lipid metabolism in proliferating cervical cancer cells partially through p53 degradation. Increased lipogenesis in cancer cells is induced by the upregulation of lipid metabolizing enzymes, such as ATP citrate lyase (ACLY), acetyl-CoA carboxylase (ACC), fatty acid synthase (FASN), through the activation of sterol regulatory element-binding proteins (SREBPs). These enzymes represent metabolic checkpoints involved in lipid biogenesis in carcinogenesis. Also shown is the AMPK induced block of lipid (SREBPs, ACC) and protein synthesis (mTOR).

HR-HPV E6 and E7 also deregulate cellular energetics favoring the Warburg effect, as well as protein and lipid synthesis. The expression of E6 and E7 not only inhibits p53 and pRB, but also activates additional signaling pathways that may be equally important for transformation, such as the phosphatidylinositol 3-kinase (PI3K)/Akt/mammalian target of rapamycin (mTOR) signaling cascade [51]. One important component in these responses is the oncogenic mTOR, which promotes protein synthesis and, under certain conditions, induces or inhibits autophagy (alternative energy source). The induction of autophagy is important in carcinogenesis because it can generate both metabolic intermediates and ATP to help cancer cells to survive starvation. Key regulators of $\mathrm{mTOR}$ are $\mathrm{PKB} / \mathrm{Akt}$ (positive regulators) and AMP-activated protein kinase (AMPK), which respond to an increased AMP/ATP ratio under conditions of low energy to repress mTOR. Thus, active $\mathrm{PKB} / \mathrm{Akt}$ can promote the anabolic energy consuming pathways (such as fatty acid and protein synthesis) 
necessary for cell growth and activated AMPK drives the catabolic, energy-producing responses (such as fatty acid oxidation) that are needed under conditions of metabolic stress (Figure 2) [39,51-55] and (Figure 3) [39,56-62]. Since these are frequently activated pathways in HPV-induced cancers, understanding the mechanisms by which the $\mathrm{PI} 3 \mathrm{~K} / \mathrm{Akt} / \mathrm{mTOR}$ and p53/AMPK/SREBPs signaling pathways contribute to cervical carcinogenesis will help to develop novel strategies for preventing and treating HPV-induced cancers [51]. For example, HR-HPV E6 proteins activate mTORC1 signaling and increase translation through $\mathrm{S} 6 \mathrm{~K}$ and $4 \mathrm{E}-\mathrm{BP} 1$ activation contributing to carcinogenesis [52,53]. The HPV16 E6 oncoprotein induces prolonged receptor protein tyrosine kinase signaling and mTORC1 activation irrespective of growth factor deprivation [53]. The hypoxiainducible factor $1 \alpha$ (HIF-1 $\alpha$ ), a ubiquitously expressed transcriptional regulator involved in induction of numerous genes associated with angiogenesis and tumor growth, is highly increased by the E6 oncoprotein [63]. Thus, E6 activated HIF-1a contributes to the Warburg effect through coordinated upregulation of glycolysis and downregulation of oxidative phosphorylation.

The HR-HPV E7 oncoprotein favors the Warburg effect partially through binding to the glycolytic enzyme type M2 pyruvate kinase (M2-PK), suggesting that the interaction of E7 with M2-PK may be linked to the transforming potential of the viral oncoprotein [64]. Phosphorylated, activated protein kinase $\mathrm{B}$ ( $\mathrm{PKB} / \mathrm{Akt})$ is normally dephosphorylated by the PP2A phosphatase [65]. Activation of PKB/Akt by the HPV16 E7 oncoprotein occurs through a mechanism involving inhibition of PP2A [65]; in this regard, it was described that the cancerous inhibitor of protein phosphatase $2 \mathrm{~A}$ (CIP2A) is overexpressed in cervical cancer and upregulated by the HPV16 E7 oncoprotein [66]. In normal cells metabolic pathways are tightly regulated to allow cell growth and survival, depending on the conditions. Nutrient availability supports the synthesis of proteins, lipids and nucleic acids for cell growth and proliferation, whereas starvation triggers a series of responses to restrict cell proliferation, maximize energy production and help cell survival. p53 is emerging as an important player in the regulation of metabolic stress and several studies have shown that p53 inhibits glycolysis and activates oxidative phosphorylation [67] and therefore should counteract the increase in glycolysis that is characteristic of cancers. Unfortunately, the very low p53 levels observed in cervical cancer and derived cell lines reverse these protective tumor suppressive effects. p53 can inhibit the expression of the glucose transporters GLUT1 and GLUT4 while increasing the expression of TIGAR to block the glycolytic flux (Figure 3) $[39,56-62]$. p53 also indirectly impedes glycolysis by restricting the activation of the nuclear factor (NF- $\mathrm{kB}$ ) and the expression of glycolysis-promoting genes such as GLUT3. The inhibition of glycolysis induced by p53 is paralleled by the ability of p53 to drive oxidative phosphorylation [39] (Figure 3) [39,56-62], and these actions are obviously reversed by the HR-HPV E6 oncoproteins [67].

There is increasing evidence that cancer cells show specific alterations in lipid metabolism that generates multiple bioactive lipid molecules responsible for the activation and regulation of many signaling pathways like cell proliferation or metastasis [68,69]. Increased lipogenesis in cancer cells is induced by the upregulation of lipid metabolizing enzymes, and also coupled to other common metabolic pathways such as those related with glycolytic or glutaminolytic flux. During aerobic glycolysis, glucose is transformed in pyruvate leading to an increase in the mitochondrial concentration of citrate, an intermediate of the Krebs cycle. In highly proliferating cells, mitochondrial citrate is exported to the cytosol and used as a precursor for lipogenic pathways. Citrate is cleaved by ATP-citrate lyase (ACLY) to generate acetyl-CoA and oxaloacetate; acetyl-CoA represents the start-up molecule for newly synthesized lipids. ACLY, as well as acetyl-CoA carboxylase (ACC) and fatty acid synthase (FASN), are transcriptionally regulated by sterol regulatory element-binding proteins (SREBPs).

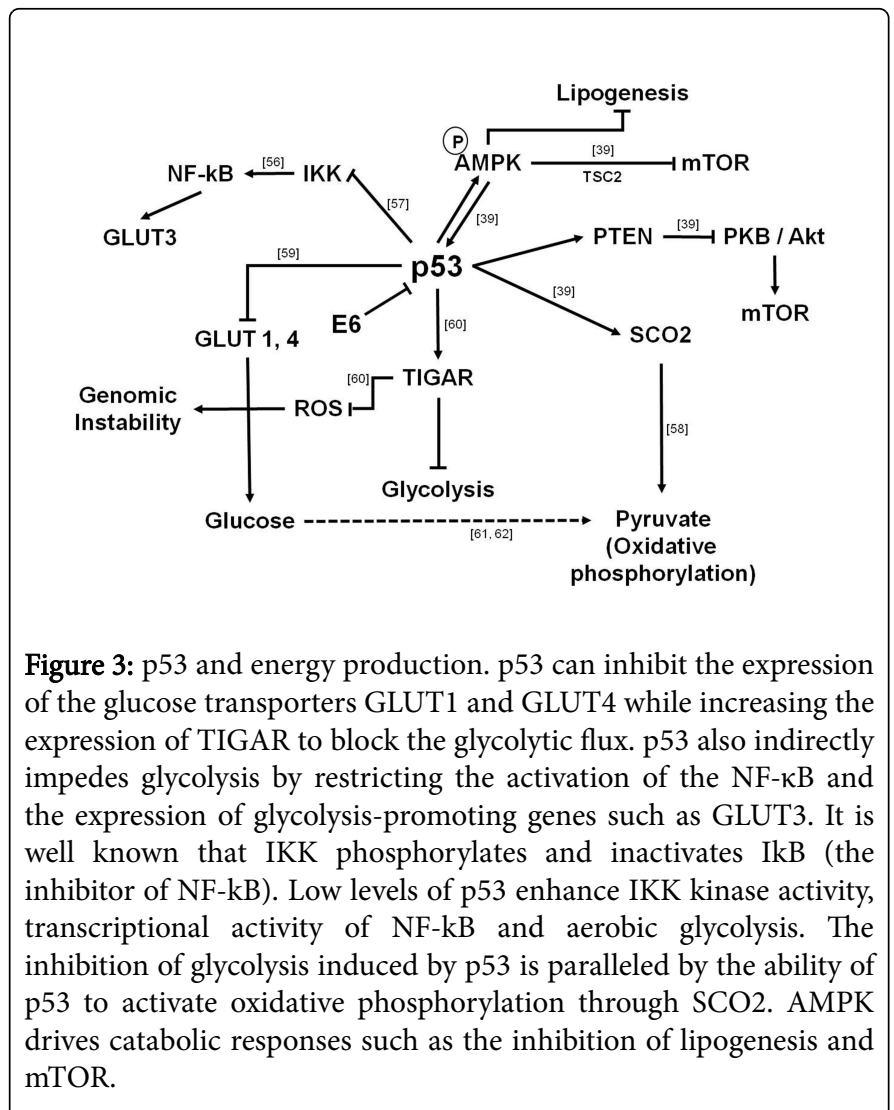

These enzymes represent highly characterized metabolic checkpoints involved in the progression of cancer development and for which several pharmacological approaches are under evaluation [54,69]; Interestingly, the SREBPs transcription factors are activated by PKB/Akt and down regulated by AMPK [55], suggesting that HPV E6 and E7 oncoproteins could upregulate this pathway through several mechanisms. In this regard, E6 can upregulate miR-21 which in turn down regulates PTEN, a known inhibitor of the Akt pathway. In addition, p53 protein degradation induced by the E6 oncoprotein (Figure 2) [52-55], indirectly inhibits the expression of several genes that negatively regulate the Akt pathway (IGF-BP3, PTEN, AMPK) [70-72]. On the other hand, the E7 oncoprotein can upregulate the Akt pathway through inhibition of pRB (Figure 4) [73-77] or by binding to $\mathrm{PP} 2 \mathrm{~A}$; in this case $\mathrm{PKB} / \mathrm{Akt}$ signaling is kept high due to dephosphorylation inhibition $[65,78,79]$.

\section{HR-HPVs E6 and E7 Oncoproteins Cause Genomic Instability}

HPV16 E6 and E7 proteins promote gene amplification, structural chromosomal alterations and centrosome replication errors leading to aneuploidy and polyploidy. Thus, HPV immortalized cell lines are characterized by gain and loss of whole chromosomes [80]. HPV 
oncoproteins and genomic instability is a characteristic phenotype of many malignant tumors including cervical cancer [81,82]. The genomic instability and cancer can result from the presence of extra centrosomes and the subsequent formation of multipolar mitoses promoting chromosome missegregation and ultimately aneuploidy [83]. Tri-polar mitoses are a hallmark of HR-HPV-associated carcinomas [82]. Furthermore, the frequency of aneuploidy increases with both malignant grade and tumor aggressiveness in HR-HPVassociated lesions. In the context of high-risk HPV, centrosome amplification is observed in cells expressing episomal HPV16 genomes, which underscores that viral integration is not required for the disruption of centrosome duplication control [84]. Besides aneuploidy, structural chromosomal instability is a critical factor for malignant progression. This is evidenced by the enhanced rate of tumor formation in patients with mutations in DNA repair pathway genes such as BRCA1, BRCA2 or the mismatch-repair (MMR) pathway [85].

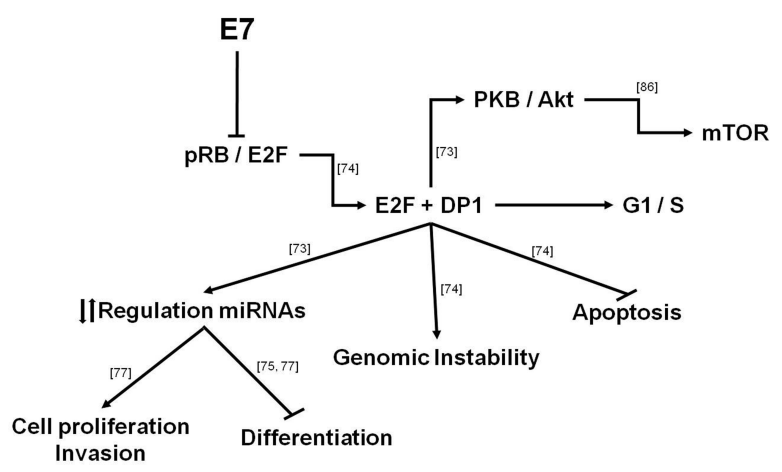

Figure 4: E7 binds pRB, allowing the release of E2F. E2F binds cell cycle regulator DP1, causing to advance cell cycle from G1 to $\mathrm{S}$, decreased apoptosis and increased genomic instability. E2F can also increase cell proliferation and invasion, as well as a differentiation inhibition through upregulation or dowregulation of miRNAs.

Unrepaired, broken DNA can promote gene translocations or gene amplifications/deletions, which may provide a growth advantage to cells through gain of oncogenes or loss of tumor suppressors [85]. Several lines of evidence show that expression of HPV16 E6 and E7 can independently induce structural chromosomal instability $[86,87]$. The expression of the HPV E6 oncoprotein increases two genomedestabilizing events, aberrant cell division and dysregulated centrosome duplication [88]. Typically, this leads to the stabilization of p53, which prevents further propagation of cells containing these errors [88], but HPV E6 restricts the stabilization of p53, leading not only to continued cellular proliferation but also to further accumulation of mutagenic events, suggesting that HPV E6 protein would increase the genomic instability in p53-dependent ways [88] (Figure 5). Likewise, it has been observed that manipulation of cellular DNA damage repair machinery facilitates propagation of human papillomaviruses, and expression of the E7 viral protein activates the DNA damage response [89]. This suggests once more that the E7 oncoprotein causes genomic instability (Figure 4) [73-77].

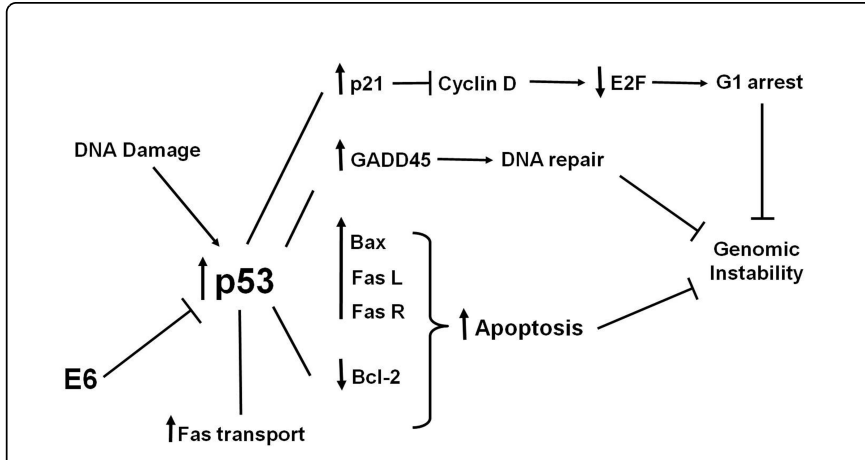

Figure 5: The expression of HPV E6 degradates p53, leading not only to continued cellular proliferation but also to further accumulation of mutagenic events, suggesting that HPV E6 protein would increase the genomic instability in p53-dependent ways.

\section{E6 and E7 of High-Risk HPVs Enhance the Epithelial- Mesenchymal Transition}

It is known that the epithelial cells are connected by specialized membrane structures, such as adherens junctions, tight junctions and desmosomes that are characterized by a localized distribution of adhesion molecules including cadherins, catenins and integrins (reviewed in Thiery et al., and Gónzalez-Mariscal et al., [90,91]). Cells undergoing the epithelial-mesenchymal transition (EMT) lose their typical epithelial characteristics and acquire mesenchymal properties (reviewed in Thiery et al., [90]). Importantly, studies show that cervical tumor cells can reactivate the developmental EMT process during HRHPV-induced tumor cell invasion and metastasis [92,93]. Several investigations reported that expression of both E6 and E7 oncoproteins of HPV type 16 induces morphological conversion from cobblestoneshaped epithelium to spindle-shaped mesenchyme-like phenotype [92-94]. These morphological changes are consistent with the expression of EMT transcription factors such as SLUG, TWIST, ZEB1, ZEB2 and SNAIL 1, induced by both E6 and E7 oncoproteins $[92,94,95]$. This results in the down-regulation of the epithelial marker E-cadherin and concomitant up-regulation of the mesenchymal markers N-cadherin, fibronectin, and vimentin [92,94,95]. Therefore, it can be seen that both E6 and E7 oncoproteins of HPV type 16 could directly or indirectly through the deregulation of transcription factors alter the expression of these EMT proteins. E6 and E7 each contribute to EMT, a key step in activating invasion and metastasis [4,94]. Moreover, E7 has been reported to induce angiogenesis [96].

\section{HR-HPVs E6 and E7 Oncoproteins Modify the miRNAs Expression in Cervical Cancer}

MicroRNAs (miRNAs or miR) are a class of small non coding RNAs of 18-25 nucleotides in length [97]. The main function of the miRNAs is to modulate gene expression post transcriptionally [97]. Specific miRNAs are classified as oncogenes (oncomirs) or tumor suppressor genes based on their expression patterns in tumors [97,98]. Likewise, some miRNAs possess a tumor suppressive/proapoptotic role while others have anti-apoptotic/proliferation-promoting roles in the cell $[98,99]$. In cervical cancer (CC), HR-HPVs infection can affect the pattern of miRNAs expression through the E6 and E7 oncoproteins contributing to viral pathogenesis [77]. Interestingly, the miRNA 
expression profile in CC can discriminate between normal and tumor tissue and the extraordinary stability of miRNAs makes it suitable to serve as diagnostic and prognostic biomarkers of cancer [100]. Here we summarize the role of HR-HPV E6 and E7 oncoproteins on miRNAs expression.

\section{Deregulation of MicroRNAs by the E6 Oncoprotein}

The HR-HPV E6 oncoprotein is capable of regulating the expression of numerous coding and noncoding genes including miRNAs through the degradation of p53 [101]. In this regard, HPV16 E6 oncoprotein was found to decrease the expression of tumor suppressive miR-23b, which leads to the increase in the expression of urokinase-type plasminogen activator (uPA), inducing the migration of human cervical carcinoma cells [102].

miR-34a has also been identified as a direct transcriptional target of p53 [103]. Interestingly, Wang et al. showed that the E6 oncoprotein expressed from HPV16 or HPV18 inhibits the expression of tumor suppressive miR-34a by destabilization of p53, resulting in cell proliferation [104], which is consistent with the observed ability of miR-34a to downregulate genes promoting cell cycle such as Cyclin E2, CDK4, E2F1, E2F3, and E2F5 [101].

Although tumor suppressive miR-218 is not defined as a transcriptional target of $\mathrm{p} 53$, this miRNA is downregulated in the presence of the E6 oncoprotein [105]; conversely, RNA interference of E6/E7 oncogenes increased miR-218 expression. It was observed that the exogenous expression of miR-218 decreases LAMB3 transcript and protein levels [105]. LAMB3 protein is part of the polymeric cell surface receptor laminin 5 that is involved in cell migration and tumorigenicity [106]. These results suggest that the downregulation of miR-218 by E6 and the consequent overexpression of LAMB3 contribute to cervical tumorigenesis [105].

Previous studies have shown that the tumor suppressive miR-1246 is a transcriptional target of p53 [107] and that the expression level of miR-1246 in CC tissue was significantly lower than in the control group [108]. Likewise, loss-of-function studies have demonstrated that the miR-1246 expression level is increased when HPV16 E6 gene is knocked down in a CC cell line [108]. Taking together, these observations suggest that the expression of miR-1246 is negatively related with HPV16 E6 expression [108].

On the other hand, it has been observed that the expression of miR-21 is significantly higher while let-7a is lower in CC tissues compared to pre-cancer and normal control tissues. Shishodia et al. observed that the miR-21 level corresponds to the level of E6 oncoprotein. On the contrary, the let-7a levels were consistently low in cervical lesions expressing high levels of E6 [70,71]. Low let-7a induced a high STAT3 mRNA level, while the overexpression of miR-21 was found associated with the diminution of TIMP-3 and PTEN tumor suppressors, the last being a negative regulator of STAT3; elevated level of STAT3 induces high expression of MMP-2 and MMP-9 [70,71]. This indicates that aberrant STAT3-mediated events include upregulation of MMPs expression and activity, which could partly be facilitated through activation of miR-21 via suppression of both TIMP-3 and PTEN expression. Based on these data, it was concluded that higher miR-21 and reduced let-7a expression levels are strongly associated with increased expression and activation of STAT3 as well as with E6 overexpression in cervical carcinogenesis [70,71].

\section{Deregulation of MicroRNAs by the E7 Oncoprotein}

The HR-HPV E7 oncoprotein upregulates the expression of the oncogenic miR-15b through the E2F transcription factor in CC [109], which correlates with the increase in CCNA2, CCNB1, CCNB2 and MCM7 expression [109]. Interestingly, expression of miR-15a, miR-15b, and miR-16 is positively regulated by E2F1 and E2F3 $[109,110]$, suggesting a common mechanism for the upregulation of these miRNAs by the E7 oncoprotein.

miR-203 is a critical molecule for inducing the transition of keratinocytes from a proliferative state in undifferentiated basal cells to a nonproliferative status in differentiated suprabasal cells [111]. One of the identified targets of the tumor suppressive miR-203 is p63, which is a transcription factor that regulates the balance between epithelial proliferation and differentiation [75]. This important miRNA is negatively regulated by the HR-HPV E7 oncoprotein causing a differentiation block, which may occur through the mitogen-activated protein (MAP) kinase/protein kinase C (PKC) pathway [75] (Figure 4) [73-77].

On the other hand, it was reported that the HPV16 E7 oncoprotein is capable of upregulate the expression of miR-27b to promote proliferation and invasion in CC [78]. A target of miR-27b is the peroxisome proliferator-activated receptor $\gamma(\operatorname{PPAR} \gamma)$, which plays a significant role in suppressing CC progression by downregulating the sodium-hydrogen exchanger isoform 1 [78]; the inhibition of miR-27b diminished the ability of HPV16 E7 oncoprotein to suppress PPAR $\gamma$ or activate $\mathrm{Na}^{+} / \mathrm{H}^{+}$exchanger 1 (NHE1) expression [78]. These data suggest that miR-27b is upregulated by HPV16 E7 oncoprotein to inhibit PPAR $\gamma$ expression promoting proliferation and invasion in cervical carcinoma cells [78] (Figure 4) [73-77].

\section{Deregulated MicroRNAs by both E6 and E7 Oncoproteins}

miR-29 is considered a candidate miRNA with potential tumor suppressor activity [77]. This miRNA suppresses cell growth and its expression levels are much lower in tumor cell lines or tumors derived from cervical tissue $[112,113]$. CDK6 is a direct target of miR-29, so downregulation of miR-29 in CC results in upregulation of CDK6 and cell cycle deregulation. $\mathrm{Li}$ et al. found that CDK6 was positively correlated with E6/E7 mRNA expression [112]. Furthermore, overexpression of CDK6, CDK4 and cyclin D1 are present in all cases of CC [114]. Thus downregulation of miR-29 and upregulation of CDK6 and cyclin D1 by either E6 or E7 oncoprotein cooperate to further promote cell cycle progression in CC.

It is known that the miR-155 oncogene is an important miRNA upregulated by the TGF/Smad4 pathway. This miRNA contributes to the TGF induced EMT and cell migration by targeting tumor suppressor RhoA (ARHGAP12) [115]. RhoA plays critical roles in several essential cell functions, including decrease in cellular adhesion, increase in motility, polarity, and also is an important regulator of cell junction formation and stability [116]. Previously, it was reported that E6 and E7 oncoproteins from HPV16 induce activation of TGF [117], which has been implicated in metastatic CC [118]. Otherwise, RhoA has been reported to be downregulated in CC, suggesting negative regulation by E6 and E7 oncoproteins through TGF [119]. Additionally, miR-155 has been found to be overexpressed in CC [112]. These data suggest that miR-155 may play an important role in cell migration and invasion by targeting RhoA and indicate that this oncomir is a potential therapeutic target for cervical cancer. 
miR-31 is considered an oncogene in CC. Zheng et al., found that the expression level of miR-31 was significantly higher in CC patients than in normal individuals [120], and that expression of the HPV16 E6/E7 oncoproteins increased miR-31 levels. Furthermore, they reported that the overexpression of miR-31 can promote cell proliferation and enhance the migration and invasion abilities of CC cells [120], suggesting an additional mechanism for E6/E7-induced cervical carcinogenesis.

It has been reported that miR-9 plays a prominent role in proliferation, migration and differentiation [121]. Liu et al., observed that miR-9 was upregulated in HR-HPV-positive tumors [122]. Moreover, miR-9 was strongly upregulated in HPV16-positive CC tumors compared with both HPV18-positive and HPV-negative tumors [122]. Strikingly, they found that miR-9 was significantly upregulated by both E6 and E7 oncoproteins, and that the activation of this miRNA by the HPV E6 oncoprotein was independent of the p53 pathway. Further target validation and functional cell biology analyses showed that HPV-induced miR-9 activation led to increased cell motility by downregulating multiple gene targets involved in cell migration, which may contribute to the progression of CC [122].

Remarkably, some of the most abundant miRNAs found to be significantly affected by E6/E7 silencing in HPV-positive cancer cells are known to be involved in the regulation of cell proliferation, senescence and apoptosis [123]. Specifically, continuous E6/E7 oncoprotein expression is necessary to maintain high intracellular levels of miR-7, miR-629, miR-378a, miR378f, miR-17, and miR-186, which have all been linked to pro-tumorigenic activities [123]. On the other hand, continuous E6/E7 expression is also linked to a decrease in the intracellular concentrations of miR-23a, miR-23b, miR-27b, and miR-143, all linked to anti-tumorigenic activities [123]. Thus, the miRNAs expression may be a potential diagnostic/prognostic marker and may show therapeutic potential for the treatment of HPV-linked premalignant and malignant lesions.

\section{Cancer Stem Cell-Related Markers in Cervical Cancer}

It is known that tumors are composed of heterogeneous cell subpopulations [124]. The cancer stem cells (CSCs) are a minority subpopulation of tumoral cells endowed with properties such as selfrenewal, high proliferation rate, and the ability to generate heterogenic lineages of cancer cells [125]. CSCs are responsible for chemoresistance and relapse and have been identified in solid tumors including cervical cancer [126,127], through an experimental strategy that combines sorting of tumor cell subpopulations, on the basis of the differential surface expression markers and functional transplantation of these cells into appropriate animal models $[128,129]$. The mechanisms of chemoresistance include high expression levels of adenosine triphosphate-binding cassette transporters, self-renewal, high DNA repair capacity, as well as activated $\mathrm{Wnt} / \beta$-catenin and Notch signaling $[127,129,130]$

Several potential cervical epithelial stem cell markers including Aldehyde dehydrogenase 1 (ALDH1), Oct3/4, Sox2, Nanog and CD49f have been used to identify cervical CSCs [127,131]. It has been observed that the expression of these markers is increased in cervical squamous cell carcinoma and that their expression is closely related to clinical survival in cervical cancer patients, suggesting an important role of these markers in predicting clinical prognosis in this neoplasia [127]. Otherwise, Oct3/4, Sox 2 and Nanog are essential transcription factors for the maintenance of pluripotent stem cells [132].
Knockdown of these genes in cervical cancer cell lines can result in tumor cell apoptosis, decreased tumor sphere formation (enriched for CSCs) and inhibition of tumor formation in xenograft tumor models [133], suggesting that Oct4, Sox 2 and Nanog are CSC biomarkers in cervical cancer [131].

Oct3/4 plays an important role in stem cell pluripotency and differentiation $[134,135]$. Li et al., found that Oct3/4 is responsible for maintaining self-renewal of cervical CSCs, besides contributing to the initiation of cervical carcinoma [136]. It was observed that Oct3/4 positive cell populations can evade chemotherapy and eventually lead to tumor recurrence $[133,136]$; Oct3/4 expression is also associated with radiation-resistance and unfavorable survival in locally advanced cervical squamous cell carcinoma [133]. It is interesting that Oct3/4 overexpression is associated with shorter disease-free and overall survival which is possibly related with residual tumor after resection [131].

Sox2 is involved in the regulation of the cell cycle, DNA repair and self-renewal in stem cells [138]. Recently it was reported that high expression of Sox 2 is associated with a lack of cell differentiation and may contribute to cell migration and invasion in a cervical cancer cell line [133]. Likewise, Ji et al., found that the patients with high Sox2 expression had significantly worse overall survival [138]. These findings provide evidence that high Sox 2 expression can be regarded as a predictor of poor prognosis for cervical cancer patients.

ALDH1 participates in the synthesis of retinoic acid, and is thought to be involved in cellular differentiation and proliferation via the retinoid pathway $[139,140]$. Many recent studies investigating the ALDH1 gene or protein report its impact on the clinical outcome of cervical cancer patients [127]. ALDH1 has been proposed as a CSC marker and may be associated with tumor progression and recurrence [141]. It was reported that ALDH1 is a factor of poor prognosis for cervical carcinoma [142]; equally, it has been found that high ALDH1 expression is significantly related to recurrence and low overall survival in cervical squamous cell carcinoma patients [127]. Moreover, it has been reported that high ALDH1 expression is significantly associated with low clinical chemotherapy response rate and clinical non-response in cervical cancer patients [143].

Activation of the Wnt $/ \beta$-catenin, Notch and Hedgehog signaling pathways is characteristic of the cancer stem cells, which have been shown to have one or more aberrations in various signalling pathways; however, abnormal activity of pathways that control self-renewal, and have important roles in embryonic development and differentiation, which include Notch, Hedgehog, and Wnt/ $\beta$-catenin, are probably most crucial to the tumorigenicity of CSCs [144]. Recently, it has been found that $\mathrm{Wnt} / \beta$-catenin signaling is a very important pathway in the maintenance of CSCs [145]. A striking cytoplasmic localization of $\beta$ catenin was found in cervical cancer suggesting that the presence of $\beta$ catenin in the cytoplasm may be related to the malignant phenotype of epithelial cells from the uterine cervix [138]. Moreover, Wang, et al., found that the $\mathrm{Wnt} / \beta$-catenin signaling pathway is involved in the resistance to radiotherapy in cervical cancer [146]. Interestingly, HPV16-associated cervical tumorigenesis is synergized by GSK3 $\beta$ inactivation and overactivation of the Wnt/ $\beta$-catenin pathway [147]. It was recently reported that a decrease in Wnt7A expression augmented cell proliferation and migration of cervical cancer-derived cells [148].

The Notch signalling pathway, which is necessary for several biological processes such as cellular proliferation, differentiation and apoptosis is considered an oncogenic pathway [144]. Aberrant Notch 
signalling is associated with several human diseases including cancers where it alters the developmental state of the cells and consequently maintains them in a proliferative or undifferentiated state [149]. It was reported the over-expression of Notch-3 in patients with precancerous cervical lesions and cervical cancer as compared to normal cervix tissue [149]. This supports that the activation and deregulation of Notch signalling may provide a permissive environment for the development of early pre-cancerous lesions which may lead to proliferation of HR-HPV associated cervical tumors [149,150].

The hedgehog signaling pathway is involved in cell proliferation and differentiation during embryonic development [151,152]. Xuan, et al., observed that the hedgehog-signaling pathway was extensively activated in carcinoma and CIN of uterine cervix [153]. Additionally, they reported that expression of the hedgehog-signaling pathway is greatly enhanced over the CIN I/II/III-carcinoma sequence in the uterine cervix [153]. They suggested that the inappropriate activation of the hedgehog-signaling pathway and inactivation of p53 by E6 proteins from HR-HPV exert a synergistic effect on the uterine cervix carcinogenesis [153].

Thus, we have briefly seen in this minireview that multiple processes and signaling pathways are altered by the HR-HPV E6 and E7 oncoproteins in cervical carcinogenesis $[1,11]$; among other affected processes, genomic instability plays a central role leading to mutations in cellular genes, which cooperate with the initial necessary steps induced by HR-HPV oncoproteins, including inactivation of two important tumor suppressor pathways (pRB and p53). Cervical cancer may represent an important model to understand the different oncogenic mechanisms and processes involved not only in this neoplasia but also in the development of other human malignancies. Strategies to improve the different aspects of immune surveillance and the understanding of the multiple cellular pathways directly or indirectly modified by the HR-HPV E6 or E7 oncoproteins must be considered in optimal and effective cervical cancer therapeutic approaches. Likewise, the miRNAs and cancer stem cell-related markers expression could serve as novel molecular targets for the treatment of HPV positive cervical cancer.

\section{Acknowledgment}

The authors would like to thank Enrique García-Villa (CINVESTAV-IPN) and Mariano Enoc Cortes-Malagon (Unidad de Investigación, Hospital Juárez de México) for reading of this manuscript.

\section{References}

1. Tommasino M (2014) The human papillomavirus family and its role in carcinogenesis. Semin Cancer Biol 26: 13-21.

2. Chen Y, Williams V, Filippova M, Filippov V, Duerksen-Hughes P (2014) Viral carcinogenesis: factors inducing DNA damage and virus integration. Cancers 6: 2155-2186.

3. Gariglio P, Gutiérrez J, Cortés E, Vázquez J (2009) The role of retinoid deficiency and estrogens as cofactors in cervical cancer. Arch Med Res 40: 449-465.

4. Mesri EA, Feitelson M, Munger K (2014) Human viral oncogenesis: a cancer hallmarks analysis. Cell Host \& Microbe 15:266-282.

5. Datta SD, Saraiya M (2011) Cervical cancer screening among women who attend sexually transmitted diseases (STD) clinics: background paper for 2010 STD Treatment Guidelines. Clin Infect Dis 53: S153-S159.
6. Shulzhenko N, Lyng H, Sanson GF, Morgun A (2014) Ménage à trois: an evolutionary interplay between human papillomavirus, a tumor, and a woman. Trends Microbiol 22: 345-353.

7. Vande Pol SB, Klingelhutz AJ (2013) Papillomavirus E6 oncoproteins. Virology 445: 115-137.

8. Grabowska AK, Riemer AB (2012) The invisible enemy-how human papillomaviruses avoid recognition and clearance by the host immune system. Open Virol J 6: 249-256.

9. Song DAN, Li H, Li H, Dai J (2015) Effect of human papillomavirus infection on the immune system and its role in the course of cervical cancer. Oncol Lett 10: 600-606.

10. McLaughlin-Drubin ME, Meyers J, Munger K (2012) Cancer associated human papillomaviruses. Curr Opin Virol 2: 459-466.

11. Moody CA, Laimins LA (2010) Human papillomavirus oncoproteins: pathways to transformation. Nat Rev Cancer 10: 550-560.

12. Wentzensen N, Vinokurova S, Doeberitz MVK (2004) Systematic review of genomic integration sites of human papillomavirus genomes in epithelial dysplasia and invasive cancer of the female lower genital tract. Cancer Res 64: 3878-3884.

13. Ghittoni R, Accardi R, Hasan U, Gheit T, Sylla B, et al. (2010) The biological properties of E6 and E7 oncoproteins from human papillomaviruses. Virus Genes 40: 1-13.

14. Howie HL, Katzenellenbogen RA, Galloway DA (2009) Papillomavirus E6 proteins. Virology 384: 324-334.

15. Banks L, Pim D, Thomas M (2012) Human tumour viruses and the deregulation of cell polarity in cancer. Nat Rev Cancer 12: 877-886.

16. Cobrinik D (2005) Pocket proteins and cell cycle control. Oncogene 24: 2796-2809.

17. Dimova DK, Dyson NJ (2005) The E2F transcriptional network: old acquaintances with new faces. Oncogene 24: 2810-2826.

18. Zhang B, Chen W, Roman A (2006) The E7 proteins of low- and high-risk human papillomaviruses share the ability to target the pRB family member p130 for degradation. Proc Natl Acad Sci USA 103: 437-442.

19. Attwooll C, Oddi S, Cartwright P, Prosperini E, Agger K, et al. (2005) A novel repressive E2F6 complex containing the polycomb group protein, $\mathrm{EPC} 1$, that interacts with EZH2 in a proliferation-specific manner. J Biol Chem 280: 1199-1208.

20. Trimarchi JM, Fairchild B, Verona R, Moberg K, Andon N, et al. (1998) E2F-6, a member of the E2F family that can behave as a transcriptional repressor. Proc Natl Acad Sci USA 95: 2850-2855.

21. McLaughlin-Drubin ME, Huh KW, Münger K (2008) Human papillomavirus Type 16 E7 oncoprotein associates with E2F6. J Virol 82: 8695-8705.

22. McLaughlin-Drubin ME, Crum CP, Münger K (2011) Human papillomavirus E7 oncoprotein induces KDM6A and KDM6B histone demethylase expression and causes epigenetic reprogramming. Proc Natl Acad Sci USA 108: 2130-2135.

23. Gutiérrez J, García-Villa E, Ocadiz-Delgado R, Cortés-Malagón EM, Vázquez J, et al. (2015) Human papillomavirus type 16 E7 oncoprotein upregulates the retinoic acid receptor-beta expression in cervical cancer cell lines and K14E7 transgenic mice. Mol Cell Biochem 408: 261-272.

24. Zhang B, Laribee RN, Klemsz MJ, Roman A (2004) Human papillomavirus type $16 \mathrm{E} 7$ protein increases acetylation of histone $\mathrm{H} 3$ in human foreskin keratinocytes. Virology 329: 189-198.

25. Bodily JM, Mehta KPM, Laimins LA (2011) Human papillomavirus E7 enhances hypoxia-inducible factor 1-mediated transcription by inhibiting binding of histone deacetylases. Cancer Res 71:1187-1195.

26. Johannsen E, Lambert PF (2013) Epigenetics of human papillomaviruses. Virology 445: 205-212.

27. Kim YT, Zhao M (2005) Aberrant cell cycle regulation in cervical carcinoma. Yonsei Med J 46: 597-613.

28. Tommasino M, Adamczewski J, Carlotti F, Barth C, Manetti R, et al. (1993) HPV16 E7 protein associates with the protein kinase p33CDK2 and cyclin A. Oncogene 8: 195-202. 
29. He W, Staples D, Smith C, Fisher C (2003) Direct activation of cyclindependent kinase 2 by human papillomavirus E7. J Virol 77: 10566-10574.

30. McLaughlin-Drubin ME, Münger K (2009) The Human papillomavirus E7 oncoprotein. Virology 384: 335-344.

31. Herber R, Liem A, Pitot H, Lambert PF (1996) Squamous epithelial hyperplasia and carcinoma in mice transgenic for the human papillomavirus type 16 E7 oncogene. J Virol 70: 1873-1881.

32. Riley RR, Duensing S, Brake T, Münger K, Lambert PF, et al. (2003) Dissection of human papillomavirus E6 and E7 function in transgenic mouse models of cervical carcinogenesis. Cancer Res 63: 4862-4871.

33. Ibarra Sierra E, Díaz Chávez J, Cortés-Malagón EM, Uribe-Figueroa L, Hidalgo-Miranda A, et al. (2012) Differential gene expression between skin and cervix induced by the E7 oncoprotein in a transgenic mouse model. Virology 433: 337-345.

34. Cortés-Malagón EM, Bonilla-Delgado J, Díaz-Chávez J, Hidalgo-Miranda A, Romero-Cordoba S, et al. (2013) Gene expression profile regulated by the HPV16 E7 oncoprotein and estradiol in cervical tissue. Virology 447: 155-165.

35. Pim D, Banks L (2010) Interaction of viral oncoproteins with cellular target molecules: infection with high-risk vs. low-risk human papillomaviruses. APMIS 118: 471-493.

36. Martinez-Zapien D, Ruiz FX, Poirson J, Mitschler A, Ramirez J, et al. (2016) Structure of the E6/E6AP/p53 complex required for HPVmediated degradation of p53. Nature 529: 541-545.

37. Li Y, Qi H, Li X, Hou X, Lu X, et al. (2015) A novel dithiocarbamate derivative induces cell apoptosis through p53-dependent intrinsic pathway and suppresses the expression of the E6 oncogene of human papillomavirus 18 in HeLa cells. Apoptosis 20: 787-795.

38. Lagunas-Martínez A, Madrid-Marina V, Gariglio P (2010) Modulation of apoptosis by early human papillomavirus proteins in cervical cancer. Biochim Biophys Acta 1805: 6-16.

39. Vousden KH, Ryan KM (2009) p53 and metabolism. Nat Rev Cancer 9: 691-700.

40. Patel D, Huang SM, Baglia LA, McCance DJ (1999) The E6 protein of human papillomavirus type 16 binds to and inhibits co-activation by CBP and $\mathrm{p} 300$. EMBO J 18: 5061-5072.

41. Xie X, Piao L, Bullock BN, Smith A, Su T, et al. (2014) Targeting HPV16 E6-p300 interaction reactivates p53 and inhibits the tumorigenicity of HPV-positive head and neck squamous cell carcinoma. Oncogene 33: 1037-1046.

42. Nguyen ML, Nguyen MM, Lee D, Griep AE, Lambert PF (2003) The PDZ ligand domain of the human papillomavirus type 16 E6 protein is required for E6's induction of epithelial hyperplasia in vivo. J Virol 77: 6957-6964

43. Watson RA, Thomas M, Banks L, Roberts S (2003) Activity of the human papillomavirus E6 PDZ-binding motif correlates with an enhanced morphological transformation of immortalized human keratinocytes. J Cell Sci 116: 4925-4934.

44. Mantovani F, Banks L (2001) The human papillomavirus E6 protein and its contribution to malignant progression. Oncogene 20: 7874-7887.

45. Klingelhutz AJ, Foster SA, McDougall JK (1996) Telomerase activation by the E6 gene product of human papillomavirus type 16. Nature 380: 79-82.

46. Horikawa I, Barrett JC (2003) Transcriptional regulation of the telomerase hTERT gene as a target for cellular and viral oncogenic mechanisms. Carcinogenesis 24: 1167-1176.

47. Gewin L, Myers H, Kiyono T, Galloway DA (2004) Identification of a novel telomerase repressor that interacts with the human papillomavirus type-16 E6/E6-AP complex. Genes Dev 18: 2269-2282.

48. Veldman T, Liu X, Yuan H, Schlegel R (2003) Human papillomavirus E6 and Myc proteins associate in vivo and bind to and cooperatively activate the telomerase reverse transcriptase promoter. Proc Natl Acad Sci USA 100: 8211-8216.
49. Oronsky B, Oronsky N, Fanger G, Parker C, Caroen S, et al. (2014) Follow the ATP: tumor energy production: a perspective. Anticancer Agents Med Chem 14: 1187-1198.

50. Jang M, Kim SS, Lee J (2013) Cancer cell metabolism: implications for therapeutic targets. Experimental \& Molecular Medicine 45: e45.

51. Zhang L, Wu J, Ling MT, Zhao L, Zhao KN (2015) The role of the $\mathrm{PI} 3 \mathrm{~K} / \mathrm{Akt} / \mathrm{mTOR}$ signalling pathway in human cancers induced by infection with human papillomaviruses. Mol Cancer 14: 87.

52. Spangle JM, Münger K (2010) The human papillomavirus type 16 E6 oncoprotein activates mTORC1 signaling and increases protein synthesis. J Virol 84: 9398-9407.

53. Spangle JM, Munger K (2013) The HPV16 E6 oncoprotein causes prolonged receptor protein tyrosine kinase signaling and enhances internalization of phosphorylated receptor species. PLoS Pathog 9: e1003237.

54. Lettieri Barbato D, Vegliante R, Desideri E, Ciriolo MR (2014) Managing lipid metabolism in proliferating cells: new perspective for metformin usage in cancer therapy. Biochim Biophys Acta 1845: 317-324.

55. Zahra-Bathaie S, Ashrafi M, Azizian M, Tamanoi F (2016) Mevalonate pathway and human cancers. Current Molecular Pharmacology 9: 1-9.

56. DeBerardinis RJ, Mancuso A, Daikhin E, Nissim I, Yudkoff M, et al. (2007) Beyond aerobic glycolysis: Transformed cells can engage in glutamine metabolism that exceeds the requirement for protein and nucleotide synthesis. Proc Natl Acad Sci USA 104: 19345-19350.

57. Kawauchi K, Araki K, Tobiume K, Tanaka N (2009) Loss of p53 enhances catalytic activity of IKK $\beta$ through O-linked $\beta$ - $\mathrm{N}$-acetyl glucosamine modification. Proc Natl Acad Sci USA 106: 3431-3436.

58. Matoba S, Kang JG, Patino WD, Wragg A, Boehm M, et al. (2006) p53 regulates mitochondrial respiration. Science 312: 1650-1653.

59. Schwartzenberg-Bar-Yoseph F, Armoni M, Karnieli E (2004) The tumor suppressor p53 down-regulates glucose transporters GLUT1 and GLUT4 gene expression. Cancer Res 64: 2627-2633.

60. Bensaad K, Tsuruta A, Selak MA, Vidal MNC, Nakano K, et al. (2006) TIGAR, a p53-inducible regulator of glycolysis and apoptosis. Cell 126: $107-120$.

61. Lebedeva MA, Eaton JS, Shadel GS (2009) Loss of p53 causes mitochondrial DNA depletion and altered mitochondrial reactive oxygen species homeostasis. Biochim Biophys Acta 1787: 328-334.

62. Kulawiec M, Ayyasamy V, Singh KK (2009) p53 regulates mtDNA copy number and mitocheckpoint pathway. J Carcinog 8: 8.

63. Guo Y, Meng X, Ma J, Zheng Y, Wang Q, et al. (2014) Human papillomavirus 16 E6 contributes HIF-1a induced Warburg effect by attenuating the VHL-HIF-1 $\alpha$ interaction. Int J Mol Sci 15: 7974-7986.

64. Zwerschke W, Mazurek S, Massimi P, Banks L, Eigenbrodt E, et al. (1999) Modulation of type $\mathrm{M}(2)$ pyruvate kinase activity by the human papillomavirus type 16 E7 oncoprotein. Proc Natl Acad Sci USA 96: 1291-1296.

65. Pim D, Massimi P, Dilworth SM, Banks L (2005) Activation of the protein kinase B pathway by the HPV-16 E7 oncoprotein occurs through a mechanism involving interaction with PP2A. Oncogene 24: 7830-7838.

66. Liu J, Wang X, Zhou G, Wang H, Xiang L, et al. (2011) Cancerous inhibitor of protein phosphatase $2 \mathrm{~A}$ is overexpressed in cervical cancer and upregulated by human papillomavirus 16 E7 oncoprotein. Gynecol Oncol 122: 430-436.

67. Hernández-Reséndiz I, Román-Rosales A, García-Villa E, López-Macay A, Pineda E, et al. (2015) Dual regulation of energy metabolism by p53 in human cervix and breast cancer cells. Biochim Biophys Acta 1853: 3266-3278.

68. Huang C, Freter C (2015) Lipid metabolism, apoptosis and cancer therapy. Int J Mol Sci 16: 924-949.

69. Peck B, Schulze A (2016) Lipid desaturation: the next step in targeting lipogenesis in cancer? FEBS J.

70. Shishodia G, Verma G, Srivastava Y, Mehrotra R, Das BC, et al. (2014) Deregulation of microRNAs Let-7a and miR-21 mediate aberrant STAT3 
signaling during human papillomavirus-induced cervical carcinogenesis: role of E6 oncoprotein. BMC Cancer 14: 996.

71. Shishodia G, Shukla S, Srivastava Y, Masaldan S, Mehta S, et al. (2015) Alterations in microRNAs miR-21 and let-7a correlate with aberrant STAT3 signaling and downstream effects during cervical carcinogenesis. Mol Cancer 14: 116.

72. Feng Z (2010) p53 regulation of the IGF-1/AKT/mTOR pathways and the endosomal compartment. Cold Spring Harb Perspect Biol 2: a001057.

73. Chen J (2015) Signaling pathways in HPV-associated cancers and therapeutic implications. Rev Med Virol 1: 24-53.

74. Huh K, Zhou X, Hayakawa H, Cho JY, Libermann TA, et al. (2007) Human papillomavirus type $16 \mathrm{E} 7$ oncoprotein associates with the cullin 2 ubiquitin ligase complex, which contributes to degradation of the retinoblastoma tumor suppressor. J Virol 81: 9737-9747.

75. Melar-New M, Laimins LA (2010) Human papillomaviruses modulate expression of microRNA 203 upon epithelial differentiation to control levels of p63 proteins. J Virol 84: 5212-5221.

76. Mendoza MC, Er EE, Blenis J (2011) The Ras-ERK and PI3K-mTOR pathways: cross-talk and compensation. Trends Biochem Sci 36: 320-328.

77. Gómez-Gómez Y, Organista-Nava J, Gariglio P (2013) Deregulation of the miRNAs expression in cervical cancer: human papillomavirus implications. Biomed Res Int 2013: 407052.

78. Zhang S, Liu F, Mao X, Huang J, Yang J, et al. (2015) Elevation of miR-27b by HPV16 E7 inhibits PPAR $\gamma$ expression and promotes proliferation and invasion in cervical carcinoma cells. Int J Oncol 47: 1759-1766.

79. Menges CW, Baglia LA, Lapoint R, McCance DJ (2006) Human papillomavirus type 16 E7 up-regulates AKT activity through the retinoblastoma protein. Cancer Res 66: 5555-5559.

80. Morales-Sánchez A, Fuentes-Pananá EM (2014) Human viruses and cancer. Viruses 6: 4047-4079.

81. von Knebel Doeberitz M (2002) New markers for cervical dysplasia to visualise the genomic chaos created by aberrant oncogenic papillomavirus infections. Eur J Cancer 38: 2229-2242.

82. Duensing S, Münger K (2004) Mechanisms of genomic instability in human cancer: Insights from studies with human papillomavirus oncoproteins. Int J Cancer 109: 157-162.

83. Boveri $\mathrm{T}$ (2008) Concerning the origin of malignant tumours by Theodor Boveri. Translated and annotated by Henry Harris. J Cell Sci 1: 1-84.

84. Duensing S, Duensing A, Flores ER, Do A, Lambert PF, et al. (2001) Centrosome abnormalities and genomic instability by episomal expression of human papillomavirus type 16 in raft cultures of human keratinocytes. J Virol 75: 7712-7716.

85. Khanna KK, Jackson SP (2001) DNA double-strand breaks: signaling, repair and the cancer connection. Nat Genet 27: 247-254

86. Duensing S, Münger K (2002) The human papillomavirus type 16 E6 and E7 oncoproteins independently induce numerical and structural chromosome instability. Cancer Res 62: 7075-7082.

87. Korzeniewski N, Spardy N, Duensing A, Duensing S (2011) Genomic instability and cancer: lessons learned from human papillomaviruses. Cancer Lett 305: 113-122.

88. Wallace NA, Robinson K, Galloway DA (2014) Beta human papillomavirus E6 expression inhibits stabilization of p53 and increases tolerance of genomic instability. J Virol 88: 6112-6127.

89. Wallace NA, Galloway DA (2014) Manipulation of cellular DNA damage repair machinery facilitates propagation of Human Papillomaviruses. Semin Cancer Biol 26: 30-42.

90. Thiery JP, Sleeman JP (2006) Complex networks orchestrate epithelialmesenchymal transitions. Nature Review Molecular Cell Biology 7: 131-142.

91. González-Mariscal L, Díaz-Coránguez M, Quirós M (2013) Regulation of tight junctions for therapeutic advantages. Tight Junctions in Cancer Metastasis 19: 197-246.

92. Jung YS, Kato I, Kim HRC (2013) A novel function of HPV16-E6/E7 in epithelial-mesenchymal transition. Biochem Biophys Res Commun 435: 339-344.
93. Qureshi R, Arora H, Rizvi MA (2015) EMT in cervical cancer: Its role in tumour progression and response to therapy. Cancer Lett 356: 321-331.

94. Hellner K, Mar J, Fang F, Quackenbush J, Münger K (2009) HPV16 E7 oncogene expression in normal human epithelial cells causes molecular changes indicative of an epithelial to mesenchymal transition. Virology 391: 57-63.

95. Azzimonti B, Dell'Oste V, Borgogna C, Mondini M, Gugliesi F, et al. (2009) The epithelial-mesenchymal transition induced by keratinocyte growth conditions is overcome by E6 and E7 from HPV16, but not HPV8 and HPV38: characterization of global transcription profiles. Virology 388: 260-269.

96. Chen W, Li F, Mead L, White H, Walker J, et al. (2007) Human papillomavirus causes an angiogenic switch in keratinocytes which is sufficient to alter endothelial cell behavior. Virology 367: 168-174.

97. Calin GA, Croce CM (2006) MicroRNA signatures in human cancers. Nat Rev Cancer 6: 857-866.

98. Kent OA, Mendell JT (2006) A small piece in the cancer puzzle: microRNAs as tumor suppressors and oncogenes. Oncogene 25: 6188-6196.

99. Miska EA (2005) How microRNAs control cell division, differentiation and death. Curr Opin Genet Dev 15: 563-568.

100. Wang X, Tang S, Le SY, Lu R, Rader JS, et al. (2008) Aberrant expression of oncogenic and tumor-suppressive microRNAs in cervical cancer is required for cancer cell growth. PLoS One 3: e2557.

101. He L, He X, Lim LP, de Stanchina E, Xuan Z, et al. (2007) A microRNA component of the p53 tumour suppressor network. Nature 447: 1130-1134.

102. Au Yeung CL, Tsang TY, Yau PL, Kwok TT (2011) Human papillomavirus type 16 E6 induces cervical cancer cell migration through the p53/ microRNA-23b/urokinase-type plasminogen activator pathway. Oncogene 30: 2401-2410.

103. Chang TC, Wentzel EA, Kent OA, Ramachandran K, Mullendore M, et al. (2007) Transactivation of miR-34a by p53 broadly influences gene expression and promotes apoptosis. Mol Cell 26: 745-752.

104. Wang X, Wang HK, McCoy JP, Banerjee NS, Rader JS, et al. (2009) Oncogenic HPV infection interrupts the expression of tumor-suppressive miR-34a through viral oncoprotein E6. RNA 15: 637-647.

105. Martinez I, Gardiner AS, Board KF, Monzon FA, Edwards RP, et al. (2008) Human papillomavirus type 16 reduces the expression of microRNA-218 in cervical carcinoma cells. Oncogene 27: 2575-2582.

106. Calaluce R, Bearss DJ, Barrera J, Zhao Y, Han H, et al. (2004) Laminin-5 $\beta 3 \mathrm{~A}$ expression in LNCaP human prostate carcinoma cells increases cell migration and tumorigenicity. Neoplasia 6: 468-479.

107. Liao JM, Zhou X, Zhang Y, Lu H (2012) MiR-1246: a new link of the p53 family with cancer and Down syndrome. Cell Cycle 11: 2624-2630.

108. Yang Y, Xie YJ, Xu Q, Chen JX, Shan NC, et al. (2015) Down-regulation of miR-1246 in cervical cancer tissues and its clinical significance. Gynecol Oncol 138: 683-688.

109. Myklebust MP, Bruland O, Fluge $\varnothing$, Skarstein A, Balteskard L, et al. (2011) MicroRNA-15b is induced with E2F-controlled genes in HPVrelated cancer. Br J Cancer 105: 1719-1725.

110. Ofir M, Hacohen D, Ginsberg D (2011) MiR-15 and miR-16 are direct transcriptional targets of E2F1 that limit E2F-induced proliferation by targeting cyclin E. Mol Cancer Res 9: 440-447.

111. Yi R, Poy MN, Stoffel M, Fuchs E (2008) A skin microRNA promotes differentiation by repressing 'stemness'. Nature 452: 225-229.

112. Li Y, Wang F, Xu J, Ye F, Shen Y, et al. (2011) Progressive miRNA expression profiles in cervical carcinogenesis and identification of HPVrelated target genes for miR-29. J Pathol 224: 484-495.

113. Pereira PM, Marques JP, Soares AR, Carreto L, Santos MAS (2010) MicroRNA expression variability in human cervical tissues. PLoS One 5: e11780.

114. Arvanitis DA, Spandidos DA (2008) Deregulation of the G1/S phase transition in cancer and squamous intraepithelial lesions of the uterine cervix: a case control study. Oncology Rep 20: 751-760. 
115. Kong W, Yang H, He L, Zhao JJ, Coppola D, et al. (2008) MicroRNA-155 is regulated by the transforming growth factor beta/Smad pathway and contributes to epithelial cell plasticity by targeting RhoA. Mol Cell Biol 28: 6773-6784.

116. Perez-Moreno M, Jamora C, Fuchs E (2003) Sticky business: orchestrating cellular signals at adherens junctions. Cell 112: 535-548.

117. Peralta-Zaragoza O, Bermúdez-Morales V, Gutiérrez-Xicotencatl L, Alcocer-González J, Recillas-Targa F, et al. (2006) E6 and E7 oncoproteins from human papillomavirus type 16 induce activation of human transforming growth factor betal promoter throughout Sp1 recognition sequence. Viral Immunol 19: 468-480.

118. Noordhuis MG, Fehrmann RSN, Wisman GBA, Nijhuis ER, van Zanden JJ, et al. (2011) Involvement of the TGF-beta and beta-catenin pathways in pelvic lymph node metastasis in early-stage cervical cancer. Clin Cancer Res 17: 1317-1330.

119. Ahn WS, Bae SM, Lee JM, Namkoong SE, Han SJ, et al. (2004) Searching for pathogenic gene functions to cervical cancer. Gynecol Oncol 93: 41-48.

120. Zheng W, Liu Z, Zhang W, Hu X (2015) miR-31 functions as an oncogene in cervical cancer. Arch Gynecol Obstet 292: 1083-1089.

121. Yuva-Aydemir Y, Simkin A, Gascon E, Gao FB (2011) MicroRNA-9: Functional evolution of a conserved small regulatory RNA. RNA Biol 8: 557-564.

122. Liu W, Gao G, Hu X, Wang Y, Schwarz JK, et al. (2014) Activation of miR-9 by human papillomavirus in cervical cancer. Oncotarget 5: 11620-11630.

123. Honegger A, Schilling D, Bastian S, Sponagel J, Kuryshev V, et al. (2015) Dependence of intracellular and exosomal microRNAs on viral E6/E7 oncogene expression in HPV-positive tumor cells. PLoS Pathog 11: e1004712.

124. Codony-Servat J, Rosell R (2015) Cancer stem cells and immunoresistance: clinical implications and solutions. Transl Lung Cancer Res 4: 689-703.

125. Gupta PB, Chaffer CL, Weinberg RA (2009) Cancer stem cells: mirage or reality? Nat Med 15: 1010-1012.

126. Wang LI, Guo H, Lin C, Yang L, Wang X (2014) Enrichment and characterization of cancer stem-like cells from a cervical cancer cell line. Mol Med Rep 9: 2117-2123.

127. Hou T, Zhang W, Tong C, Kazobinka G, Huang X, et al. (2015) Putative stem cell markers in cervical squamous cell carcinoma are correlated with poor clinical outcome. BMC Cancer 15: 785.

128. Organista-Nava J, Gómez-Gómez Y, Gariglio P (2013) Embryonic stem cell-specific signature in cervical cancer. Tumour Biology 35: 1727-1738.

129. López J, Poitevin A, Mendoza-Martínez V, Pérez-Plasencia C, GarcíaCarrancá A (2012) Cancer-initiating cells derived from established cervical cell lines exhibit stem-cell markers and increased radioresistance. BMC Cancer 12: 48-48.

130. Gottesman MM, Fojo T, Bates SE (2002) Multidrug resistance in cancer: role of ATP-dependent transporters. Nat Rev Cancer 2: 48-58.

131. Kim BW, Cho H, Choi CH, Ylaya K, Chung JY, et al. (2015) Clinical significance of OCT4 and SOX2 protein expression in cervical cancer. BMC Cancer 15: 1015.

132. Johansson H, Simonsson S (2010) Core transcription factors, Oct4, Sox2 and Nanog, individually form complexes with nucleophosmin (Npm1) to control embryonic stem (ES) cell fate determination. Aging (Albany NY) 2: $815-822$.

133. Shen L, Huang X, Xie X, Su J, Yuan J, et al. (2014) High expression of SOX2 and OCT4 indicates radiation resistance and an independent negative prognosis in cervical squamous cell carcinoma. J Histochem Cytochem 62: 499-509.

134. Rosner MH, Vigano MA, Ozato K, Timmons PM, Poirie F, et al. (1990) A POU-domain transcription factor in early stem cells and germ cells of the mammalian embryo. Nature 345: 686-692.
135. Rodda DJ, Chew JL, Lim LH, Loh YH, Wang B, et al. (2005) Transcriptional regulation of Nanog by OCT4 and SOX2. J Biol Chem 280: 24731-24737.

136. Li SW, Wu XL, Dong CL, Xie XY, Wu JF, et al. (2015) The differential expression of OCT4 isoforms in cervical carcinoma. PLoS One 10: e0118033.

137. Peng C, Li N, Ng YK, Zhang J, Meier F, et al. (2012) A unilateral negative feedback loop between miR-200 microRNAs and Sox2/E2F3 controls neural progenitor cell-cycle exit and differentiation. J Neurosci 32: 13292-13308.

138. Ji J, Wei X, Wang Y (2014) Embryonic stem cell markers Sox-2 and OCT4 expression and their correlation with Wnt signal pathway in cervical squamous cell carcinoma. Int J Clin Exp Pathol 7: 2470-2476.

139. Li J, Feng ZC, Yeung FSH, Wong MRM, Oakie A, et al. (2013) Aldehyde dehydrogenase 1 activity in the developing human pancreas modulates retinoic acid signalling in mediating islet differentiation and survival. Diabetologia 57: 754-764.

140. Lohberger B, Rinner B, Stuendl N, Absenger M, Liegl-Atzwanger B, et al. (2012) Aldehyde dehydrogenase 1, a potential marker for cancer stem cells in human sarcoma. PLoS One 7: e43664.

141. Knudsen ES, Dervishaj O, Kleer CG, Pajak T, Schwartz GF, et al. (2013) EZH2 and ALDH1 expression in ductal carcinoma in situ: Complex association with recurrence and progression to invasive breast cancer. Cell Cycle 12: 2042-2050.

142. Yao T, Wu Z, Liu Y, Rao Q, Lin Z (2014) Aldehyde dehydrogenase 1 (ALDH1) positivity correlates with poor prognosis in cervical cancer. J Int Med Res 42: 1038-1042.

143. Xie Q, Liang J, Rao Q, Xie X, Li R, et al. (2015) Aldehyde dehydrogenase 1 expression predicts chemoresistance and poor clinical outcomes in patients with locally advanced cervical cancer treated with neoadjuvant chemotherapy prior to radical hysterectomy. Ann Surg Oncol 23: 163-170.

144. Takebe N, Miele L, Harris PJ, Jeong W, Bando H, et al. (2015) Targeting notch, hedgehog, and Wnt pathways in cancer stem cells: clinical update. Nat Rev Clin Oncol 12: 445-464.

145. Holland JD, Klaus A, Garratt AN, Birchmeier W (2013) Wnt signaling in stem and cancer stem cells. Curr Opin Cell Biol 25: 254-264.

146. Wang T, Liu Z, Shi F, Wang J (2016) Pin1 modulates chemo-resistance by up-regulating FoxM1 and the involvements of Wnt/ $\beta$-catenin signaling pathway in cervical cancer. Mol Cell Biochem 413: 179-187.

147. Rath G, Jawanjal P, Salhan S, Nalliah M, Dhawan I (2015) Clinical significance of inactivated glycogen synthase kinase $3 \beta$ in HPV-associated cervical cancer: Relationship with Wnt/ $\beta$-catenin pathway activation. Am J Reprod Immunol 73: 460-478.

148. Ramos-Solano M, Meza-Canales ID, Torres-Reyes LA, Alvarez-Zavala M, Alvarado-Ruíz L, et al. (2015) Expression of Wnt genes in cervical cancerderived cells: Implication of Wnt7A in cell proliferation and migration. Exp Cell Res 335: 39-50.

149. Tripathi R, Rath G, Jawanjal P, Sharma S, Singhal P, et al. (2014) Clinical impact of de-regulated Notch-1 and Notch-3 in the development and progression of HPV-associated different histological subtypes of precancerous and cancerous lesions of human uterine cervix. PLoS One 9: e98642.

150. Zhang P, Li H, Yang B, Yang F, Zhang LL, et al. (2014) Biological significance and therapeutic implication of resveratrol-inhibited Wnt, Notch and STAT3 signaling in cervical cancer cells. Genes Cancer 5: 154-164.

151. Ingham PW, McMahon AP (2001) Hedgehog signaling in animal development: paradigms and principles. Genes Dev 15: 3059-3087.

152. Jia Y, Wang Y, Xie J (2015) The Hedgehog pathway: role in cell differentiation, polarity and proliferation. Arch Toxicol 89: 179-191.

153. Xuan YH, Jung HS, Choi YL, Shin YK, Kim HJ, et al. (2006) Enhanced expression of hedgehog signaling molecules in squamous cell carcinoma of uterine cervix and its precursor lesions. Mod Pathol 19: 1139-1147. 